\title{
Exploring the Potential Role of Inflammation as an Etiological Process in ASD
}

\author{
Rebecca Elias $^{1}$ • Juliana B. Sullivan ${ }^{1,3} \cdot$ Yong W. Lee ${ }^{2}$ Susan W. White ${ }^{1}$
}

Received: 13 January 2015 / Accepted: 26 May 2015 /Published online: 6 June 2015

(C) Springer Science+Business Media New York 2015

\begin{abstract}
The heterogeneity in the behavioral presentation of autism spectrum disorder (ASD) may be surpassed only by the level of heterogeneity in its etiology. There are diverse pathways to the singular diagnostic outcome of ASD, and several etiological risk factors have been proposed in recent years. This review paper examines the role of inflammation as one possible etiologic factor in ASD, juxtaposed in the context of research on the role of inflammation in other psychiatric disorders. Human, animal, and postmortem studies of inflammation in ASD were surveyed, and their direct and indirect contributions to developing potential inflammation-based treatments, as well as potential preventative considerations, in ASD were reviewed. Although the mechanisms that link inflammation and ASD remain unknown, there exists a sizable multidisciplinary literature suggesting inflammation as a trans-etiological process.
\end{abstract}

Keywords Autism spectrum disorder · Inflammation · Etiology $\cdot$ Treatment

Understanding mechanisms that may be implicated in the etiology and frequent co-occurrence of biological conditions and mental health disorders is of considerable interest to the scientific community (Rommelse et al. 2011; Tuchman et al.

Rebecca Elias

relias@vt.edu

1 Department of Psychology, Virginia Tech, Blacksburg, VA 24061, USA

2 Department of Biomedical Engineering and Mechanics, Virginia Tech, Blacksburg, VA 24061, USA

3 Edward Via College of Osteopathic Medicine-VA Campus, Blacksburg, VA 24060, USA
2010). Identification of such mechanisms may promote conceptual parsimony in explaining complex clinical phenomena as well as variability in expression across individuals. It is generally thought that core underlying mechanisms do not correspond perfectly to any singular diagnosis or syndrome (e.g., Mitchell and Goldstein 2014). Rather, distinct processes are thought to influence the manifestation of several, often cooccurring, diagnostic conditions.

These mechanisms can be thought of as encompassing a trans-etiological profile, suggesting that a distinct mechanism may be associated with the expression and/or presence of symptomatology which span and comprise a variety of diverse disorders. The exploration of inflammation as a possible transetiological factor in psychopathology (and autism spectrum disorder (ASD) in particular) serves high utility as inflammation is a physiological process which integrates biological mechanisms and environmental factors. Examination of the expression of clinical disorders from a developmental perspective, particularly from a biopsychosocial lens, requires examination of genetic susceptibility, environmental risk factors, and behavioral experiences, in addition to nonobservable physiological processes. The interplay between physical processes and environmental experiences has garnered substantial support within the ASD community (e.g., Dawson 2008). We propose a trans-etiological framework of inflammation to examine how inherent or developed physiological processes interplay with the expression or inhibition of psychopathology.

\section{Method}

\section{Search Strategy}

A comprehensive search of the scientific literature was conducted by two independent researchers. Searches were 
conducted in several biomedical electronic databases for peerreviewed published literature (e.g., PUBMED, PsycINFO, MEDLNE, and Web of Science). The following key words were used to guide the literature search: autis*, or autism spectrum disorder (ASD), or Asperger syndrome (AS), or Asperger Disorder (AD), or Pervasive Developmental Disorder (PDD), and inflammation, or inflammatory, or cytokines, or biomarker, or oxidative stress. Additional studies were identified by reviewing personal collections and by manually searching the reference lists of original empirical articles. The search was limited to studies published between 1995 and November 2014. Inclusion criteria limited the reviewed studies to studies that (1) were published in English, (2) assessed inflammation in individuals with ASD, and (3) evaluated inflammation mitigation in ASD. Of the references identified via the electronic searches, 76 peer-reviewed papers met inclusionary criteria and were retained for review. The present literature review sought to examine human, animal, and postmortem studies of inflammation in ASD and to investigate inflammation as a possible etiological factor. Given that prior reviews on inflammation in ASD have not included all three of these approaches, the current synthesis of the literature is broad, multidisciplinary, and unique. A secondary aim was to briefly review the existing literature researching the effectiveness of treatments targeting inflammation and to comment on their potential utility in the future.

\section{Literature Review}

\section{Inflammation as a Possible Mechanism in Psychiatric Disorders}

To understand the possible pathological process of inflammation, we must first consider the rejuvinative function and normative process of inflammation in the human body. Inflammation, for the purpose of this paper, is broadly defined as a reaction to an adverse agent. Specifically, mediators of inflammation including cytokines are released in an attempt to remove an adverse agent and subsequently return the system to a stable state. If the agent is not removed in a timely fashion, inflammation results (Kumar et al. 2005). Overstimulation of the immune system in response to actual or perceived threat can prove detrimental to the body's overall systemic inflammatory response (Dinarello 2000). Swelling puts pressure on nerve endings in the affected region which, paired with the release of other mediators, can cause significant pain and potential loss of utility. In a healthy, well-functioning immune system, the invading pathogens are attacked and engulfed by phagocytic cells, specifically neutrophils and macrophages (Raven et al. 2011).

Research with adults has long theorized that inflammation acts as an etiological mechanism in the presentation of psychiatric disorders. Several studies report that depression
(Dowlati et al. 2010; Lotrich et al. 2007, 2009), bipolar disorder (Goldstein et al. 2009), neurodegenerative diseases (Nuzzo et al. 2014), and schizophrenia (Potvin et al. 2008) are associated with inflammation in some capacity. Recently, studies utilizing child participants have begun to examine inflammation as one process which is trans-etiological in nature (Mitchell and Goldstein 2014; Rossignol and Frye 2014). In children, preliminary evidence suggests that inflammation may also play a role in depression and ASD (Mitchell and Goldstein 2014). Specifically, the clinical presentation of ASD has been associated with promoting inflammation in the human body (Mitchell and Goldstein 2014).

Although the empirical support suggesting that inflammation is associated with a variety of psychiatric conditions has been established, the manner in which inflammation is tied to psychological conditions and/or its function related to etiology is unknown. The field is starting to move beyond the established simple association between inflammation and psychiatric comorbidity to determine causation and directionality, a necessary step to inform targeted treatment development.

Differing measurement approaches has limited the generalizability of the immune system's role in ASD etiology, prevention, and treatment. Varying survey methods and foci have produced a plethora of promising pathways in the etiological domain (Table 1). However, these varied methodological approaches have not yet sufficiently translated to the development of research-derived treatments. In this exploration of inflammation as a potential core process involved in ASD, we examine the mechanisms by which inflammation may occur, how inflammation can affect neural health, and potential methodological approaches for future examination of inflammation in ASD.

\section{Investigating Inflammation in ASD}

\section{Inflammation as a Potential Biomarker}

ASD is a neurodevelopmental disorder that is, for most people who are diagnosed, life course-persistent. Diagnostic criteria for ASD include difficulties in social interaction, social communication, and stereotyped repetitive behavior and interests (American Psychiatric Association 2013). Due to the clinical benefits of early identification and intervention (e.g., Dawson 2008; Dawson et al. 2010), high degree of heterogeneity within the ASD diagnosis phenotypically (Geschwind 2009; Wiggins et al. 2012), and dependence on a nosological system that relies on observed behaviors and symptoms, there has been a clinical and scientific push in recent years to identify biological markers to assist in the diagnosis of ASD and facilitate etiological hypotheses (Taylor et al. 2014; Walsh et al. 2011). Establishing biological underpinnings prior to behavioral manifestation of symptomatology has vast implications for further subcategorization of the heterogeneous disorder, 
Table 1 Summary of select reviewed studies implicating inflammation in individuals with ASD: methodologies and outcomes

\begin{tabular}{|c|c|c|c|c|}
\hline Author & $\begin{array}{l}\text { Number of } \\
\text { participants }\end{array}$ & $\begin{array}{l}\text { Chronological } \\
\text { age (in years) }\end{array}$ & Procedure & Processes implicated \\
\hline Chauhan et al. 2012 & $\begin{array}{l}\text { ASD: } 10 \\
\text { TD: } 10\end{array}$ & $\begin{array}{l}\text { ASD: } 4.5-38 \\
\text { TD: } 4.6-39.2\end{array}$ & $\begin{array}{l}\text { Measured the concentrations and } \\
\text { redox ratio of GSH and GSSG in } \\
\text { the cerebellum, frontal, temporal, } \\
\text { parietal, and occipital cortices of } \\
\text { postmortem brain tissue samples }\end{array}$ & $\begin{array}{l}\text { The levels of GSH, the levels of } \\
\text { tGSH, and the redox ratio of } \\
\text { GSH to GSSG are decreased } \\
\text { in children and adults with ASD. } \\
\text { Oxidative stress in autism is } \\
\text { brain region-specific. }\end{array}$ \\
\hline Ashwood et al. 2011 & $\begin{array}{l}\text { ASD: } 97 \\
\text { TD: } 39\end{array}$ & $\begin{array}{l}\text { ASD: } 2.8-4.1 \\
\text { TD: } 3.0-4.1\end{array}$ & $\begin{array}{l}\text { Cytokine analysis, report measures } \\
\text { of behavioral symptoms of ASD }\end{array}$ & $\begin{array}{l}\text { Increased IL-4 was associated } \\
\text { with greater deficits in } \\
\text { nonverbal communication. } \\
\text { Associations between cytokine } \\
\text { levels and lethargy, stereotypy, } \\
\text { and hyperactivity (IL-8). }\end{array}$ \\
\hline $\begin{array}{l}\text { Croonenberghs, } \\
\text { et al. } 2002\end{array}$ & $\begin{array}{l}\text { ASD: } 13 \\
\text { TD: } 13\end{array}$ & $12-18$ & $\begin{array}{l}\text { Assay of immune inflammatory } \\
\text { markers }\end{array}$ & $\begin{array}{l}\text { Increased IFN-Á and IL-1RA } \\
\text { in adolescents with ASD. }\end{array}$ \\
\hline Napolioni et al. 2013 & $\begin{array}{l}\text { ASD: } 25 \\
\text { TD: } 25\end{array}$ & $\begin{array}{l}\text { ASD: } 8.11 \\
\text { TD: } 7.44\end{array}$ & $\begin{array}{l}\text { Cytokine analysis, report measures } \\
\text { of behavioral symptoms of ASD }\end{array}$ & $\begin{array}{l}\text { No differences in cytokine levels } \\
\text { of children with ASD and } \\
\text { their TD siblings. } \\
\text { GM-CSF, IL-1 } \alpha \text {, IL-1 } \beta \text {, IL-2, IL-6, } \\
\text { IL-16, and MCP-1 pro-inflammatory } \\
\text { cytokines were inversely correlated } \\
\text { with adaptive functioning abilities. }\end{array}$ \\
\hline $\begin{array}{l}\text { El-Ansary and } \\
\text { Al-Ayadhi } 2014\end{array}$ & $\begin{array}{l}\text { ASD: } 20 \\
\text { TD: } 19\end{array}$ & $\begin{array}{l}\text { ASD: } 4-12 \\
\text { TD: } 4-11\end{array}$ & $\begin{array}{l}\text { Measurement of levels of glutamate, } \\
\text { GABA, TNF- } \alpha \text {, IL- } 6, \text { IFN- } \gamma \text {, } \\
\text { and IFI16 }\end{array}$ & $\begin{array}{l}\text { Increase in GABA and glutamate, } \\
\text { decrease in IFN- } \gamma \text { and IFI16. }\end{array}$ \\
\hline Asadabadi et al. 2012; & ASD: 1059 & Not reported & $\begin{array}{l}\text { Genotyping and analysis, ASD } \\
\text { diagnostic tools }\end{array}$ & $\begin{array}{l}\text { Positive correlations between plasma } \\
\text { MIF levels and social impairment, } \\
\text { imaginative skills, and overall } \\
\text { level of autism severity }\end{array}$ \\
\hline de Theije et al. 2014 & 41 & $\begin{array}{l}\text { Gestational day } \\
0 \text { - postnatal day } 28\end{array}$ & $\begin{array}{l}\text { Valproic acid in-utero in mice, } \\
\text { social behavioral test }\end{array}$ & $\begin{array}{l}\text { Prenatal valproic acid exposure } \\
\text { caused reduced social interaction } \\
\text { in male offspring }\end{array}$ \\
\hline Lintas et al. 2010 & $\begin{array}{l}\text { ASD: } 15 \\
\text { TD: } 14\end{array}$ & ASD: 4-30 TD: 4-30 & $\begin{array}{l}\text { Assessment of neurotropic viruses } \\
\text { in postmortem brain tissue }\end{array}$ & $\begin{array}{l}\text { Heightened combined levels of BKV, } \\
\text { JCV, and SV40 significantly more } \\
\text { frequent in ASD than in TD samples. }\end{array}$ \\
\hline Vargas et al. 2005 & $\begin{array}{l}\text { ASD: } 15 \\
\text { TD: } 12\end{array}$ & $\begin{array}{l}\text { ASD: } 5-44 \\
\text { TD: } 5-46\end{array}$ & $\begin{array}{l}\text { Analysis of postmortem brain } \\
\text { tissue and cerebrospinal fluid }\end{array}$ & $\begin{array}{l}\text { Increase in neuroglial responses in } \\
\text { participants with ASD. Increased } \\
\text { proinflammatory agents MCP-1, } \\
\text { IFN- } \gamma, \text { IL- } 8 \text {, and IP-10. }\end{array}$ \\
\hline
\end{tabular}

early diagnosis, and personalized effective treatment, as well as - potentially — prevention of full manifestation of ASD.

Biological markers (biomarkers) are key characteristics which objectively measure possible relationships between external factors and specific health outcomes (Biomarkers Definitions Working Group 2001). Consequently, they may serve as cues for identifying pathophysiological pathways that place particular subsections of the population at greater risk for a specific disorder or disease process (Schmidt 2006). Biomarkers serve as potential indicators of typical or pathological processes (Bennett and Devarajan 2011) by providing objective measurement of the body's normative response. Biomarker identification, across a range of clinical conditions, has increased exponentially over the past decade (Merchant and Klein 2011; Toledo et al. 2012). Several potential biomarkers and endophenotypes for ASD have been proposed (Ruggeri et al. 2014).

There are no established immunological biomarkers for diagnosis of ASD. However, oxidative stress serves as a biomarker for inflammation in general, and oxidative stress has been implicated in the core symptoms that characterize ASD (Chauhan and Chauhan 2006). Oxidative stress is a negative alteration of the equilibrium between the production of reactive oxygen species (free radicals) and antioxidant defenses (Betteridge 2000). Oxidative stress occurs when the body's antioxidant defense mechanisms are unable to counter the effect of endogenous and exogenous oxidative insults. There 
appears to be a potential causal pathway from oxidative stress to the inflammatory response (Chauhan and Chauhan 2006). Indicators of oxidative stress in children and adults with ASD include the following: (1) levels of glutathione (GSH), a tripeptide of glutamic acid, cysteine, and glycine; (2) oxidized glutathione (GSSG), a form of glutathione that forms disulfide linkages and acts as a hydrogen acceptor; and (3) GSH redox/ antioxidant capacity, naturally occurring antioxidants whose abnormal levels can lead to a chronic inflammatory state of the brain (Rose et al. 2012). Chauhan et al. (2012) demonstrated reduced GSH levels and increased GSSG levels in the cerebellum and temporal cortex of participants with ASD when compared to neurotypical controls. The GSH to GSSG redox ratio also suggested a GSH redox imbalance in children/young adolescents with ASD by showing a decrease of $52.8 \%$ in the cerebellum and $60.8 \%$ in the temporal cortex (Chauhan et al. 2012). This lowered ratio could be indicative of an increased risk of oxidative damage. Although several studies propose that there are increased levels of oxidative stress in brain regions of children and adults with ASD (Rossignol and Frye 2014), this remains to be empirically examined. Future research in this domain could potentially implicate oxidative stress as a biomarker for ASD, thus contributing to the literature of specific risk factors which may play a role in the ASD clinical presentation.

In addition to oxidative stress being proposed as a biomarker for ASD, DNA microarray analysis has been investigated as a means to investigate candidate genes that may be implicated in inflammation in ASD (Hu et al. 2006). Studies of differential gene expression among genetically identical twins with ASD suggested that differential gene expression in lymphoblastoid cell lines (LCL), which transformed cell lines generated from peripheral blood lymphocytes by infection with Epstein-Barr Virus (EBV), could serve as easily accessible biomarkers for ASD diagnoses by expressing a defined percentage of the genes that are typically found within ASD (Hu et al. 2006). Identifying candidate genes with this methodology is relatively feasible, as the peripheral blood lymphocyte is an easily accessible tissue. However, the investigation of possible biomarkers implicated in inflammation and ASD is not always as feasible and accessible. Examination of the cerebrospinal fluid (CSF) has been fairly promising in identifying potential biomarkers in ASD. In a study of children with ASD, the ratio of CSF to serum TNF- $\alpha$ was noticeably increased when investigating the inflammatory state of the central nervous system (Chez et al. 2007). This evaluation of ratio elevation shows promise as a generalized marker of inflammation but entails a fairly invasive procedure, conducted via a lumbar puncture (Bradstreet et al. 2010). Identification of an immunological biomarker(s) for the diagnosis of ASD has several implications. Specifically, immunological biomarkers would allow for reliance on nonbehavioral diagnostic measures which would be particularly encouraging for early diagnosis and pharmaceutical drug development.

\section{Neuroinflammation in ASD}

Neural mechanisms have been explored with respect to atypical presence of inflammation in ASD. Prenatally and throughout development, the human brain is sensitive to environmental pathogens, which ultimately impact the neurological and behavioral presentation of an individual (Bale et al. 2010; Rees and Inder 2005). It is hypothesized that immunological mechanisms in the developing brain may play an etiological role in clinical disorders, including ASD (Meyer et al. 2011; Rees and Inder 2005).

Neuroimmune research has highlighted heightened levels of cytokines and glutamate in children and adults with ASD. Cytokines are regulatory proteins that moderate host cell response to inflammation, infection, immune reactivity, and trauma. They are divided into two classes: those that promote healing and reduction of inflammation (anti-inflammatory) and those that provoke the disease's progression (pro-inflammatory; Dinarello 2000). Among the numerous classes of cytokines, interleukin-1 $\beta$ (IL-1 $\beta$ ), tumor necrosis factor- $\alpha$ (TNF- $\alpha$ ), and transforming growth factor- $\beta$ (TGF- $\beta$ ) have been implicated in ASD for their important mediating roles in the pro-inflammatory response (Ashwood et al. 2011; Croonenberghs et al. 2002; Goines and Ashwood 2012; Noriega and Savelkoul 2014; Ricci et al. 2013). Indeed, IL$1 \beta$, TNF- $\alpha$, and TGF- $\beta$ have been reported to induce inflammation, fever, and tissue destruction, and in extreme cases may lead to death in humans (Dinarello 2000). While several classes of cytokines have been identified in ASD, there appears to be nonsignificant differences between plasmacytokine levels in children with ASD and their typically developing siblings (Napolioni et al. 2013). These results suggest that specific classes of cytokines and ultimate inflammatory state may be unique to the clinical presentation of ASD. Future research in this domain may assist in early diagnosis developments among children with ASD.

Neurotransmitter signaling patterns, ratios, and levels are thoughts to contribute to the manifestation of ASD prenatally and during development (El-Ansary and Al-Ayadhi 2014). Glutamate is the major excitatory neurotransmitter in the brain that is thought to increase the pro-inflammatory effect of these cytokines to a toxic level (Coghlan et al. 2012; Hussman 2001; Pacheco et al. 2007; Miller et al. 2009). Abnormalities in glutamatergic neurotransmission have been shown to follow a similar pathophysiology of pro-inflammatory cytokines, which may be implicated in ASD (Blaylock and Strunecka 2009). Gamma aminobutyric acid (GABA) is the primary inhibitory neurotransmitter which aids in signaling and regulating processes early in development (Owens and Kriegstein 
2002). GABA and glutamate ratios are lower in children with ASD, suggesting that neurotransmitter presentation is atypical. Additionally, it is hypothesized that GABA and glutamate atypicalities may be linked with one another, with subsequent neuroinflammatory responses posited as a potential pathway implicated in the etiology of ASD (El-Ansary and Al-Ayadhi 2014). Examination of neurotransmitter presentation in ASD has vast implications as it may serve as a marker of illness, treatment response, and etiology if further evaluated.

Another potential pathological ASD implication is the macrophage inhibitory factor (MIF), a cytokine released by immune cells in the blood vessels and loose tissue and thought to regulate immune responses (Grigorenko et al. 2008). A type of glial cell in the central nervous system, microglia, senses tissue damage in the surrounding region. When activated by mediators which promote inflammation, microglia mobilize and take on phagocytic character (Miller-Keane and O'Toole 2005) while also activating cyclooxygenase- 2 systems. Social interaction deficits and stereotypical behaviors in individuals with ASD appear to be related to polymorphisms of the MIF gene, whose pathway is thought to link MIF stimulation of spinal microglia with microglia-associated neuroinflammation. Consequently, MIF has been proposed as a possible susceptibility gene in the etiology of ASD (Asadabadi et al. 2012; Grigorenko et al. 2008; Wang et al. 2011).

\section{Animal Analogues for Human Subjects with ASD}

Insight from research with animal models and postmortem human subjects has proved beneficial in the exploration of inflammation as a potential mechanism in ASD. Animal models and postmortem studies of inflammation in ASD have paved the way for understanding implications for future treatment. Animal models of ASD have served as a template for understanding symptoms, specifically repetitive behaviors, restricted interests, and deficits in social communication, as a result of maternal immune activation (MIA) on prenatal inflammation. In a 2011 study by Bunting et al., infusion of various pathologies capable of promoting inflammation correlated with heightened ASD-like behaviors. Mouse pups whose mothers had been infused with human influenza virus on the first day of gestation showed social deficits. Others showed decreased sociability and heightened anxiety when their mothers were intraperitoneally injected with polyriboinosinic:polyribocytidylic acid [poly(I:C)], an RNA analog used as a toll-like receptor (TLR3) ligand which imitates viral infection (Bunting et al. 2011; Nasu et al. 2007). It appears that specific periods of susceptibility exist, during which time inflammatory responses have a more pronounced behavioral effect in offspring. Gestational days 10.5, 12.5, and 14.5 for mouse pups seem to have particular implications on the offspring later in life, showing a wider range of ASD-like behaviors, such as more stereotypic behavior and less sociability (Bunting et al. 2011). The typical gestational period for mice spans approximately 18-22 days (Murray et al. 2010). Specifically, it appears that susceptibility during the second and third trimesters is critical to later atypical behavioral manifestation. Shi et al. (2009) found that, when infected with influenza on gestational day 9.5, mice show decreased numbers of Purkinje cells in the cerebellum. Purkinje cells collect synaptic data from outside of the cerebellum and then relay this information to the brainstem (Sudarov 2013). This finding suggests that cerebellar abnormalities may be an etiological component to the expression of ASD. More evidence needs to emerge regarding the pathology of ASD with specific relation to the cerebellum, as the mechanisms underlying some evidence of dysfunction remain unknown (Fatemi et al. 2012; Shi et al. 2009).

Mice with postnatal inflammation induced by injections of lipopolysaccharide (LPS), a large molecule made up of chemically bonded sugars and lipids, showed great anxiety and were more cautious as adults 3 days after birth (Lucchina et al. 2010). If injected 2 days later, the mice exhibited increased reactivity to social stimulation, showing a startled or violent response to other mice (Granger et al. 2006). The parietal cortex and hippocampus showed heightened levels of IL-1 $\beta$ when the rodents were injected with LPS on day 4, resulting in long-term loss of memory after a second LPS event in adulthood. Interestingly, mice that received more postnatal care prior to LPS injection on day 5 showed greater inclination for social exploration than those mice receiving less care (Hood et al. 2003). When exposed to valproic acid, associations in mice exist between ASD behavioral symptomatology and intestinal inflammation (de Theije et al. 2014). Specifically, prenatal exposure to valproic acid at the 11th day of gestation is associated with intestinal inflammation and reduced social relations in offspring. At the molecular and cellular level, MIA in mice corresponded with alterations found in humans with ASD, some manifestations of which showed long-term immune system alterations and neuroinflammation in the pups (Depino 2012). Prenatal and postnatal evidence should be further studied to understand the possible etiological mechanisms of ASD.

Neonatal exposure to inflammation has been extensively studied in the context of neuropsychological disorders (Angelidou et al. 2012; Ashwood et al. 2006; Garay et al. 2012; Prandota 2010). When disrupted by the introduction of the H1N1 strain of human influenza virus at various stages of prenatal development, genetic, brain structure, behavioral, and neurochemical abnormalities were subsequently seen in the affected mice progeny (Fatemi 2009). These varied aforementioned abnormalities were similar to those found in people with other psychological disorders such as ASD or schizophrenia (Fatemi et al. 2005, 2008; Shi et al. 2009). Similarly, Malkova et al. (2013) showed that pup and adult mouse offspring born to MIA produce less ultrasonic vocalizations, 
decreased sociability, and demonstrate increased repetitive and stereotyped behavior. There is some evidence that MIA can lead to brain abnormalities in the fetus by way of cytokines which may promote inflammation, suggesting that maternal regulation of cytokines may be of imperative importance in the expression and prevention of ASD-like symptomatology (Fatemi 2009).

\section{Postmortem Inflammatory Presentation in Individuals with ASD}

Postmortem brain studies on the possible effects on inflammation in ASD have also been conducted. In a study on the effects of polyomavirus infection on postmortem brains, the temporocortical regions of 15 adults with ASD and 13 without underwent DNA extraction (Lintas et al. 2010). Polyomaviruses are small viruses that are typically acquired during childhood. Following initial infection, they can be maintained, in a dormant state, in the kidneys and lymphocytes. This family of viruses includes BK virus (BKV), JC virus (JCV), and simian virus 40 (SV40), all of which have been clinically observed in both normal and immunocompromised adults, such as those with AIDS and transplant recipients (Bergallo et al. 2007). Through polymerase chain reaction (PCR) and DNA sequence analysis, it was observed that heightened combined levels of BKV, JCV, and SV40 were significantly more frequent $(67 \%)$ in postmortem brains of individuals having had ASD than in controls $(23 \%)$. The vertical viral transmission hypothesis is thought to be involved in this pathway, using a mechanism in which the virus camouflages itself from the body's detection as a genetic transmission mode (Lintas et al. 2010). More research is needed to determine the relation of the vertical viral transmission hypothesis in vitro with the manifestation of polyomavirus infections in postmortem brains of autistic individuals.

Immunocytochemical analysis of the postmortem brains of children and adults with ASD (aged 5-46) found that, regardless of numerous qualifiers (such as age, developmental regression, or intellectual disability), microglia and astrocytes were active in the brains of children and adults that had ASD (Vargas et al. 2005). The monocyte chemoattractant protein-1 (MCP-1) and tumor growth factor- $\beta 1$ (TGF- $\beta 1$ ) were the most prevalent in their postmortem brain tissue, as shown by cytokine profiling (Vargas et al. 2005). The study found that there was insufficient adaptive immune functioning in ASD brains, including noteworthy chronic neuroinflammation. CSF from six living children with ASD was observed through cytokine protein profiling, presenting a significant increase in MCP-1 as well. The presence of these cytokines within the neuroinflammatory pathway suggests that cytokine activity may be a chronic biomarker for ASD. Additionally, oxidative stress and inflammation markers have been found in the urine and blood of individuals with ASD, specifically in the altered sanguine levels of glutamine, glutamic acid, GABA, aspartic acid, and norepinephrine compared to controls (Ashwood and Van de Water 2004; Dawson 2008). Together, these findings point to the need for investigation of genes responsible for the body's environmental responsiveness, including immune and inflammatory responses (Herbert et al. 2006), as well as early intervention to alter the expression of these genes and subsequent brain development for better behavioral outcomes among children susceptible to ASD (Dawson 2008).

\section{Unvaried Immunological Functioning in ASD}

On the surface, an emerging literature base consistently demonstrates that immune dysregulation is associated with ASD in some capacity. However, the inferences that are drawn from this growing body of evidence should be interpreted with caution. The assertion that atypicalities in the inflammatory response system translate to the expression of comorbid autoimmune and allergic diseases is present despite limited data and replicability. A study surveying a large sample of individuals in Taiwan $(n=1,000,000)$ reported a significantly higher prevalence of allergic diseases in ASD across the lifespan and increased vulnerability to type 1 diabetes and Crohn's disease (Chen et al. 2012). No significant results linking ASD to autoimmune thyroid disease, Kawasaki disease, and celiac disease were found (Chen et al. 2012). A survey of children in Denmark indicated that there was no significant association between parental inflammatory bowel disease and ASD (Andersen Telen et al. 2014). In Sweden, researchers reported no link between ASD and active intestinal inflammation (Fernell et al. 2007). Research must extend beyond correlational and cross-sectional research to identify possible causation and directionality temporally. Varied methodologies and data analytic approaches could help ascertain if inflammation is one of the many mechanisms implicated in the presentation of ASD. Despite inconclusive overarching conclusions regarding inflammation and ASD, there have been several investigations extending this basic research to possible treatment approaches to mitigate ASD symptomatology.

\section{Emerging Treatment Approaches}

As research on inflammation as a potential etiological factor of ASD has developed, a greater breadth of intervention approaches specifically targeting inflammation has emerged (Table 2). Evaluating potential treatments for children and adults with ASD is particularly salient as the economic cost of supporting an individual across the lifespan with ASD is between 1.4 and 2.4 million dollars in the USA (Buescher et al. 2014). The largest components contributing to these figures were special education services, productivity lost, and living accommodations (Buescher et al. 2014). These 
Table 2 Summary of treatment-based research

\begin{tabular}{|c|c|c|}
\hline Approach & Mechanism & Results \\
\hline \multicolumn{3}{|l|}{ Summary of treatment studies } \\
\hline HBOT & $\begin{array}{l}\text { Increases oxygen levels to plasma } \\
\text { and tissues in the brain }\end{array}$ & $\begin{array}{l}\text { Significant improvement pretest to posttest in language } \\
\text { development, fine motor and hand-eye coordination, } \\
\text { gross motor development, self-help skills, social } \\
\text { development, social interaction, receptive language, } \\
\text { eye contact, sensory/cognitive awareness, } \\
\text { and overall functioning } \\
\text { Significant reduction of inflammation levels. }\end{array}$ \\
\hline Prednisone & Immunosuppressive glucocorticoid & $\begin{array}{l}\text { Short-term improvement in symptoms of ASD, including } \\
\text { language and social enhancement, more receptive } \\
\text { emotional abilities, purposeful directed behavior, } \\
\text { and longer sustained attention. }\end{array}$ \\
\hline Naltrexone & $\begin{array}{l}\text { Opioid antagonist affecting cytokine } \\
\text { production and overall immune response }\end{array}$ & $\begin{array}{l}\text { Improved eye contact and attention, less affective lability, } \\
\text { fewer stereotypies, and less social withdrawal, even } \\
\text { including observed desire to be close in proximity } \\
\text { to others. }\end{array}$ \\
\hline Pentoxifylline and risperidone & $\begin{array}{l}\text { Inhibit assembly of certain cytokines } \\
\text { like TNF- } \alpha \text { and IFN- } \gamma \text { that body } \\
\text { produces in times of inflammation }\end{array}$ & $\begin{array}{l}\text { Synergistically decreased irritability, social withdrawal, } \\
\text { hyperactivity/noncompliance, and improved } \\
\text { communicative speech better than risperidone } \\
\text { paired with placebo. }\end{array}$ \\
\hline Pioglitazone & $\begin{array}{l}\text { Inhibits microglial activation } \\
\text { and neuroinflammation }\end{array}$ & $\begin{array}{l}\text { Significantly improved lethargy, stereotypy and } \\
\text { hyperactivity, and irritability. }\end{array}$ \\
\hline Celecoxib and risperidone & $\begin{array}{l}\text { Targets several of most significant } \\
\text { pro-inflammatory cytokines attributed } \\
\text { to ASD-like behaviors, including } \\
\text { IL-1 } \beta, \text { IL- } 6, \text { IL- } 8 \text {, and IL-12, } \\
\text { to decrease inflammation }\end{array}$ & $\begin{array}{l}\text { Improved social withdrawal, irritability, and stereotypy } \\
\text { of children with ASD better than risperidone alone. }\end{array}$ \\
\hline
\end{tabular}

figures are most striking when compared to other illnesses with high prevalence rates that require economic support. Children with asthma, diabetes, and intellectual disabilities alone required substantially less financial support than did children with ASD (with or without comorbid intellectual disability) in the UK and the USA (Flanders et al. 2006; Mandell et al. 2006). The emotional and financial burden that ASD produces necessitates a need to investigate potential efficacious interventions. It should be noted that intervention targeting inflammation in ASD is fairly recent and the evaluation of overall treatment effectiveness is emerging and limited at present. It is hypothesized that targeting inflammatory mechanisms could possibly mitigate certain behavioral and physiological manifestations of ASD.

Hyperbaric oxygen therapy (HBOT) was identified frequently in the literature as an inflammation-based means of possibly reducing symptoms associated with ASD. However, the feasibility and efficacy of this treatment option for use in ASD are highly controversial and not well established (Whitehouse 2013). Although the US Food and Drug Administration (FDA) has approved the use of HBOT in treating a variety of other conditions, it is not approved for the treatment of ASD (U.S. Food and Drug Administration 2013).
HBOT has been promoted as a treatment for decompression sickness, severe carbon monoxide poisoning, certain injuries and skin infections, stroke, and cerebral palsy (Al-Waili et al. 2005; Bent et al. 2012; Rossignol and Rossignol 2006). HBOT serves to increase oxygen levels to plasma and tissues in the brain (Rossignol et al. 2012). The patient lies within a chamber, or monoplace, that is gradually pressurized with pure oxygen up to 2.5 times more than the average atmospheric pressure. Treatment duration ranges from $30 \mathrm{~min}$ to $2 \mathrm{~h}$ (Rossignol and Rossignol 2006). In a study of Thai children with ASD $(n=7)$ undergoing ten sessions of HBOT at 1.3 atmosphere (atm), significant improvement was shown pretreatment to posttreatment in all five domains assessed: language development, fine motor and hand-eye coordination, gross motor development, self-help skills, and social development. One quarter of the sample showed little to no response to treatment, while $75 \%$ showed marked improvement in the published case series (Chungpaibulpatana et al. 2008). A subsequent study conducted by Rossignol et al. (2007) examined C-reactive protein (CRP) levels, a marker of systemic inflammation, in children with ASD having undergone HBOT at a maximum pressure of $1.5 \mathrm{~atm}$. Post hoc analyses revealed that child participants showed a significant reduction of CRP levels following HBOT treatment. In a multicenter, double- 
blind, controlled trial, 62 children with ASD were randomly assigned to either a placebo condition, which was a slightly pressurized room with approximately normal air conditions of $21 \%$ oxygen and $1.03 \mathrm{~atm}$, or to the HBOT condition, hyperbaric treatment environment of $24 \%$ oxygen and $1.3 \mathrm{~atm}$. After 40-h long sessions, the HBOT group showed significant improvements in social interaction, receptive language, eye contact, sensory/cognitive awareness, and overall functioning compared to the control (Rossignol et al. 2009). In a study of Egyptian children with ASD, participants received 20 sessions of HBOT at $1.5 \mathrm{~atm}$ (El-baz et al. 2014). Significant improvements in sociability, behavior, sensory and cognitive awareness, and communication were seen as measured by the Autism Treatment Evaluation Checklist (ATEC; El-baz et al. 2014).

Despite considerable media attention and initial encouraging results, outcomes have been variable. Specifically, replication of results using HBOT in ASD is sparse (Ghanizadeh 2010). In a 2011 study conducted by Jepson and colleagues, direct observation play sessions were used to measure observable behaviors, including spontaneous vocalizations, physical initiations, vocal responses, physical responses, self-injurious behavior, disruption, tantrums, vocal stereotypy, and physical stereotypy. After engaging in HBOT with $24 \%$ oxygen at $1.3 \mathrm{~atm}$, there were no significant changes in the behavioral symptoms of ASD (Jepson et al. 2011). The outcome measures and methodology vary widely in the literature assessing the effectiveness of HBOT, making it difficult to conclusively assess its utility in ASD. Further, the mechanism of action in relation to inflammation is largely unknown in HBOT, as it does not change levels of cytokines which may promote inflammation (Thom 2011). While the mechanisms of change in symptomatology due to HBOT are known in a variety of other clinical uses (i.e., the healing of wounds), the active ingredients producing sustaining change in ASD cannot be derived due to the variety of methodological implementations and small sample sizes in the research literature.

In the pharmacotherapy arena, numerous medications have shown promise in reducing inflammation among children with ASD. Among them, corticosteroids such as prednisone, an immunosuppressive glucocorticoid utilized for treatment of inflammatory and autoimmune conditions (Stigler et al. 2009), have offered short-term improvement in language and social enhancement when taken in low doses (Chez and Guido-Estrada 2010; Rossignol 2009). A case study of a 3.5-year-old boy with autoimmune lymphoproliferative syndrome and comorbid ASD reported that after undergoing prednisone therapy for 1 month, the child showed an improvement in ASD symptoms characterized by better attention, language skills, awareness of environment, and purposeful directed behavior (Shenoy et al. 2000).

Endogenous opioids have likewise been suggested in ASD treatment because of their effects on immune function (Stigler et al. 2009). A dozen patients with ASD ages 7-15 were placed on naltrexone, an opioid antagonist (Scifo et al. 1996). Naltrexone has been proposed as an antiinflammatory proxy in the central nervous system (Younger et al. 2014). With treatment, patients showed significant improvement in behavioral symptoms, such as increased eye contact and attention, less affective lability, fewer stereotypies, and less social withdrawal (Scifo et al. 1996). Another immune modulator, pentoxifylline, works by inhibiting the assembly of certain cytokines like TNF- $\alpha$ and IFN- $\gamma$ that the body produces in times of inflammation (Stigler et al. 2009). Pentoxifylline, when paired with risperidone, may synergistically decrease irritability, social withdrawal, and hyperactivity/noncompliance and improve communicative speech better than risperidone paired with a placebo (Akhondzadeh et al. 2010). Pioglitazone, an antiinflammatory medication that is approved by the FDA for use in type II diabetes, was shown to significantly improve autistic symptoms like lethargy, stereotypy, hyperactivity, and irritability in a 4-month long study among 25 participants with ASD between the ages of 3 and 17, with greatest observed improvement among the younger participants (Boris et al. 2007). The proposed mechanism of action was inhibition of microglial activation and thus hindrance of neuroinflammation that typically follows (Boris et al. 2007; Emanuele and Lossano 2007).

In a recent trial to target inflammation, cyclooxygenase-2 inhibitor, celecoxib, was used in conjunction with risperidone to augment treatment response. Asadabadi et al. (2012) performed a randomized, double-blind, placebo-controlled trial of 40 children diagnosed with ASD. Inflammatory atypicalities or concerns were not criteria for inclusion. Inclusionary criteria solely consisted of a confirmed ASD diagnosis. After 10 weeks of titrated dosage, they observed that celecoxib paired with risperidone improved social withdrawal, irritability, and stereotypy of children with ASD better than risperidone alone. They hypothesized that the mechanism of action, contributing to the superior effects observed in the combined treatment condition, was enhanced immune system regulation and decreased inflammation. However, these variables were not assessed.

It is thought that celecoxib works by targeting several of the most salient or active inflammatory cytokines that have been attributed to ASD-like behaviors, including IL-1 $\beta$, IL-6, IL-8, and IL-12 (Asadabadi et al. 2012; Ashwood et al. 2011; Jyonouchi et al. 2001; Wei et al. 2011). These cytokines manifest as lethargy and stereotypy, two of the main targeted behaviors of celecoxib. Celecoxib is likewise thought to prevent kainic acid-induced neuronal death (Kunz and Oliw 2001) as well as mediate neurotoxicity from $N$-methyl-D-aspartate (NMDA) receptor, a key glutamate receptor (Tian et al. 2008). Despite encouraging preliminary clinical trials, no pharmacological agent targeting inflammation in humans 
has demonstrated consistent improvements in the social or communication domains characteristic of ASD.

Asadabadi et al. (2012) also confirmed that proinflammatory transcription factor nuclear factor- $\mathrm{kB}(\mathrm{NF}-\mathrm{kB})$, involved in normal cell function like inflammation and immune response to stress, free radicals, and cytokines, among others, has been implicated in the pathogenesis of ASD. Improper regulation of NF-kB may lead to inflammatory, autoimmune diseases, and inappropriate immune development, perhaps such as that implicated in prenatal infection during early development (Luqman and Pezzuto 2010; Patterson 2009). Celecoxib keeps more of the NF-KB in the cytoplasm from being translocated into the nucleus (Naik et al. 2011; Sareddy et al. 2012), thus providing this region of the cell with more anti-inflammatory proponents.

Treatment-based studies targeting inflammatory mechanisms in children and adults with ASD are emerging. However, as evidenced above, great care should be taken when interpreting the efficacy of these trials, as conclusions remain preliminary at this time.

\section{Forthcoming Investigations and Recommendations for Future Research}

A prominent finding from this review is the frequency with which heightened cytokine levels are present in people with ASD. The extant scientific literature, although primarily descriptive and correlational in nature, warrants controlled research to determine the possible casual role of inflammation in ASD. Within the large family of cytokines, the most validated for our investigational purposes seem to be IL-1 $\beta$ and TNF- $\alpha$ (Ashwood et al. 2011; Croonenberghs et al. 2002; Goines and Ashwood 2012; Noriega and Savelkoul 2014; Ricci et al. 2013). Their cooperation instigates a cascade of abnormal gene expression and inflammatory mediators that target the endothelium.

Although still in the early stages of field research, there are anecdotal reports of anti-cytokine therapy yielding positive results for cases of inflammation in individuals with ASD who present with problems such as rheumatoid arthritis and inflammatory bowel disease (Skurkovich et al. 2002). Anti-cytokine therapy should be further investigated as it may be beneficial to MIA. This treatment could involve neutralization by antibodies, receptor antagonists, soluble receptors, and inhibitors of proteases. Skurkovich et al. (2002) suggested that anti-cytokine therapy uses antibodies against IFN- $\alpha$, IFN- $\gamma$, TNF- $\alpha$, TNF- $\beta$, IL- 1 , IL- $1 \beta$, and IL-6. However, effectiveness of the treatment did not require removal of all of these, and it was even thought that removal of IFN- $\gamma$ alone might be sufficient due to its initiating role in the cascade effect of the cytokines. In other words, the body's homeostasis could be reestablished by simply breaking the pathological chain of events. Success of the treatment depended on the stage of the cytokine progression at which the treatment was implemented and whether or not the cytokine was an initiator for other cytokines. Other methods included the possibilities of reestablishing the repressor function of specific cells to cytokines, as well as blocking cytokine receptors with soluble receptors that absorbed cytokines traversing the body. Skurkovich et al. concluded their study with the proposal to create a drug that would utilize PEGylation, or the attachment of peptides and proteins (Roberts et al. 2002) or some other form of inhibitory mechanism to cytokine formation. A caveat does exist in that more severe cases of inflammation, such as sepsis, have shown no response to this method of treatment (Dinarello 2000).

Diet is thought to have an impact on inflammation in the body. Pilot studies assessing dietary supplements as a mechanism to reduce pro-inflammatory agents are limited. Sulforaphane, an isothiocyanate derived from broccoli, was orally administered to individuals between the ages of 13-27 daily for 18 weeks. Compared to a matched placebo group, adolescents and young adults given sulforaphane supplements during the treatment phase showed greater improvements in core ASD symptomatology (Singh et al. 2014). However, once sulforaphane treatment ceased, behavioral results reverted to baseline. These results suggest that sulforaphane may play a role in ameliorating ASD behavioral symptoms via an antiinflammatory mechanism (Singh et al. 2014). However, the small sample size of 44 and lack of replication studies at this time make these results difficult to interpret. Additionally, experimental research implementing gluten-free and/or casein-free diets has suggested a possible reduction in symptoms characteristic of ASD, although varying methodology has made these results difficult to interpret and generalize (Whiteley et al. 2013). Although considerable general and scientific attention has been given to gluten/casein-free diets, recent studies suggest that adverse consequences such as reduced bone cortical thickness may outweigh the benefits of such a discriminatory diet (Mulloy et al. 2010). Instead, researchers suggest testing for allergens on a case-by-case basis (Mulloy et al. 2010). Given that children with ASD sometimes have highly limited diets and often refuse foods of different textures or types, they may suffer nutritional consequences that exacerbate ASD symptoms and secondary problems. Many individuals with ASD, for instance, experience gastrointestinal issues, including diarrhea, cramping, constipation, and vomiting, which further impede the child's willingness to try new foods (Buie et al. 2010; Matson and Fodstad 2009). Strategies to promote more appropriate eating behaviors, such as interspersing nonpreferred foods followed by a reward with the preferred food, have yielded promising results (Matson and Fodstad 2009), but it appears that large-scale, 
replicated, and randomized trials introducing antiinflammatory foods into the diet of a child with ASD have yet to be completed. However, preliminary pilot studies appear promising.

In typically developing populations, some research suggests that certain foods (e.g., fruits, vegetables, and whole wheat) aid in inflammation modulation, largely owing to the presence of carotenoids and flavonoids in these foods (Watzl 2008), which affect the inhibition of cytokines, among other pro-inflammatory mechanisms (Serafini et al. 2010). However, the quantity of these dietary agents needed to inhibit proinflammatory mechanisms, lack of replicated research in psychiatric populations, and possible contraindication among other medications used to treat comorbid symptomatology of ASD makes these dietary supplements insufficient as a primary or complementary treatment for ASD at this time. Future research in this domain is highly encouraged as dietary supplements are minimally invasive.

Consideration of the limitations of prior empirical studies of inflammation in ASD, as previously outlined, can inform future research. Variability among results stems from inconsistency in the methodological approaches utilized and the nature of the samples, in both size and composition. With regards to size, several of the empirical studies reviewed implement small sample sizes (e.g., Chungpaibulpatana et al. 2008; Singh et al. 2014; Vargas et al. 2005) lacking sufficient power. Replications carried out with large samples across a large span of development will allow for robust results implicating inflammation as a possible etiologic factor in ASD. Additionally, improved design in this arena will allow for potential extrapolations to future intervention work. Additionally, although there is a standardized criterion for the diagnosis of ASD, the disease is heterogeneous in nature, with each individual presenting symptomatology in a unique and highly individualized manner (American Psychiatric Association 2013). Varied presentation of the condition across individuals and over time and within individuals influences the ability to make generalizations across the spectrum. This variability makes the likelihood of identifying a potent, single etiology unlikely. Thus, the overall findings should be interpreted with caution given the noted limitations.

The methodological rigor of studies linking inflammation to ASD should be improved in order to make sound generalizations and inferences to the population at large from a transetiological perspective. Specifically, future research should extend beyond traditional outcome variables measuring ASD symptomatology. Integration of the assessment of ASD behaviors and symptomatology in addition to inflammation properties will enhance our understanding of temporal patterns and possible causation. Examination of inflammation in prospective studies of siblings of diagnosed children may aid in this process. Further, the mechanisms of proposed treatments should be explored to determine the active ingredients and their relation to inflammation and later outcomes.

\section{Conclusions}

Despite a tremendous amount of well-conducted, sophisticated research on the etiology of ASD, the evidence seems to only hint at the complexity of this disorder, and it is generally held that ASD can result from multiple causes, including genetic influences and their interaction with environmental factors (Dawson 2008). Indeed, ASD is a fine example of the developmental psychopathology concept of equifinality - that there likely exist multiple pathways to the single outcome - in this case, ASD. Only a few potential associations and approaches for treatment have been highlighted here. Among them are cytokines, GSH and glutamate levels, oxidative stress, maternal systemic infection, microglial activation, polyomavirus infection, hyperbaric oxygen therapy, celecoxib and risperidone, anti-cytokine therapy, and diet. However, the aforementioned possible correlates between inflammation and ASD collectively warrant further research, specifically with regard to establishing causality which may inform future treatment in human populations.

\section{References}

Akhondzadeh, S., Fallah, J., Mohammadi, M., Imani, R., Mohammadi, M., Salehi, B., . . . Forghani, S. (2010). Double-blind placebo-controlled trial of pentoxifylline added to risperidone: effects on aberrant behavior in children with autism. Progress in NeuroPsychopharmacology \& Biological Psychiatry, 34(1), 32-36. doi: 10.1016/J.Pnpbp.2009.09.012.

Al-Waili, N., Butler, G., Beale, J., Abdullah, M., Hamilton, R., Lee, B., . . . Finkelstein, M. (2005). Hyperbaric oxygen in the treatment of patients with cerebral stroke, brain trauma, and neurologic disease. Advances in Therapy, 22(6), 659-678.

American Psychiatric Association. (2013). Diagnostic and statistical manual of mental disorders (5th ed.). Washington, DC: Author.

Andersen Telen, A. B., Ehrenstein, V., Erichsen, R., Froslev, T., \& Sørensen, H. T. (2014). Autism spectrum disorders in children of parents with inflammatory bowel disease - a nationwide cohort study in Denmark. Clinical and Experimental Gastroenterology, 4(7), 105-110.

Angelidou, A., Asadi, S., Alysandratos, K., Karagkouni, A., Kourembanas, S., \& Theoharides, T. (2012). Perinatal stress, brain inflammation and risk of autism-review and proposal. BMC Pediatrics, 12, 89. doi:10.1186/1471-2431-12-89.

Asadabadi, M., Mohammadi, M. R., Ghanizadeh, A., Modabbernia, A., Ashrafi, M., Hassanzadeh, E., Forghani, S., \& Akhondzadeh, S. (2012). Celecoxib as adjunctive treatment to risperidone in children with autistic disorder: a randomized, double-blind, placebocontrolled trial. Psychopharmacology. doi:10.1007/s00213-0122796-8. 
Ashwood, P., \& Van de Water, J. (2004). A review of autism and the immune response. Clinical and Developmental Immunology, 11(2), 165-174.

Ashwood, P., Wills, S., \& Van de Water, J. (2006). The immune response in autism: a new frontier for autism research. Leukocyte Biology, 80, $1-15$.

Ashwood, P., Krakowiak, P., Hertz-Picciotto, I., Hansen, R., Pessah, I., \& de Water, J. (2011). Elevated plasma cytokines in autism spectrum disorders provide evidence of immune dysfunction and are associated with impaired behavioral outcome. Brain, Behavior, and Immunity, 25(1), 40-45. doi:10.1016/J.Bbi.2010.08.003.

Bale, T. L., Baram, T. Z., Brown, A. S., Goldstein, J. M., Insel, T. R., McCarthy, M. M., ... Nestler, E. J. (2010). Early life programming and neurodevelopmental disorders. Biological Psychiatry, 68(4), 314-9. doi:10.1016/j.biopsych.2010.05.028.

Bennett, M., \& Devarajan, P. (2011). Characteristics of an ideal biomarker of kidney diseases. In C. L. Edelstein (Ed.), Biomarkers in kidney disease (pp. 1-24). Cincinnati: University of Cincinnati School of Medicine, Academic Press.

Bent, S., Bertoglio, K., Ashwood, P., Nemeth, E., \& Hendren, R. (2012). Brief report: Hyperbaric oxygen therapy (HBOT) in children with autism spectrum disorder: a clinical trial. Journal of Autism and Developmental Disorders, 42(6), 1127-1132. doi:10.1007/s10803011-1337-3.

Bergallo, M., Costa, C., Margio, S., Sidoti, F., Re, D., Segoloni, G. P., \& Cavallo, R. (2007). Human herpes virus 8 infection in kidney transplant patients from an area of northwestern Italy (Piemonte region). Nephrology, Dialysis, Transplantation : Official Publication of the European Dialysis and Transplant Association - European Renal Association, 22(6), 1757-1761. doi:10.1093/ndt/gfm056.

Betteridge, J. (2000). What is oxidative stress? Metabolism, 49(2), 3-8.

Biomarkers Definitions Working Group. (2001). Biomarkers and surrogate endpoints: preferred definitions and conceptual framework. Clinical Pharmacology and Therapeutics, 69(3), 89-95. doi:10. 1067/mcp.2001.113989.

Blaylock, R., \& Strunecka, A. (2009). Immune-glutamatergic dysfunction as a central mechanism of the autism spectrum disorders. Current Medicinal Chemistry, 16(2), 157-170.

Boris, M., Kaiser, C., Goldblatt, A., Elice, M., Edelson, S., Adams, J., \& Feinstein, D. (2007). Effect of pioglitazone treatment on behavioral symptoms in autistic children. Journal of Neuroinflammation, 4(1), 3. doi: 10.1186/1742-2094-4-3.

Bradstreet, J., Smith, S., Baral, M., \& Rossignol, D. (2010). Biomarkerguided interventions of clinically relevant conditions associated with autism spectrum disorders and attention deficit hyperactivity disorder. Alternative Medicine Review, 15(1), 15-32.

Buescher, A. V. S., Cidav, Z., Knapp, M., \& Mandell, D. S. (2014). Costs of autism spectrum disorders in the United Kingdom and the United States. JAMA Pediatrics, 168(8), 721-728. doi:10.1001/ jamapediatrics.2014.210

Buie, A. T., Campbell, D. B., Hyman, S. L., \& Jirapinyo, P. (2010). Evaluation, Diagnosis, and Treatment of Gastrointestinal Disorders in Individuals With ASDs : A Consensus Report. Pediatrics, 125(Supplement), S1-S18.

Bunting, R., Duffy, K., Lamb, R., San Mateo, L., Smalley, K., Raymond, H., . . Ward, C. (2011). Novel antagonist antibody to TLR3 blocks poly(I:C)-induced inflammation in vivo and in vitro. Cellular Immunology, 267(1), 9-16. doi: 10.1016/J.Cellimm.2010.10.008.

Chauhan, A., \& Chauhan, V. (2006). Oxidative stress in autism. Pathophysiology, 13(3), 171-181. doi:10.1016/j.pathophys.2006. 05.007 .

Chauhan, A., Audhya, T., \& Chauhan, V. (2012). Brain region-specific glutathione redox imbalance in autism. Neurochemical Research, 37(8), 1681-1689. doi:10.1007/S11064-012-0775-4.

Chen, M. H., Su, T. P., Chen, Y. S., Hsu, J. W., Huang, K. L., Chang, W. H., Chen, T. J., \& Bai, Y. M. (2012). Comoborbidity of allergic and autoimmune diseases in patients with autism spectrum disorder: a nationwide population-based study. Research in Autism Spectrum Disorders, 7(2013), 205-212.

Chez, M., \& Guido-Estrada, N. (2010). Immune therapy in autism: historical experience and future directions with immunomodulatory therapy. Neurotherapeutics, 7(3), 293-301.

Chez, M. G., Dowling, T., Patel, P. B., Khanna, P., \& Kominsky, M. (2007). Pediatric Neurology, 36(6), 361-365.

Chungpaibulpatana, J., Sumpatanarax, T., Thadakul, N., Chantharatreerat, C., Konkaew, M., \& Aroonlimsawas, M. (2008). Hyperbaric oxygen therapy in Thai autistic children. Journal of the Medical Association of Thailand, 91(8), 1232.

Coghlan, S., Horder, J., Inkster, B., Mendez, M. A., Murphy, D. G., \& Nutt, D. J. (2012). GABA system dysfunction in autism and related disorders: from synapse to symptoms. Neuroscience and Biobehavioral Reviews, 36(9), 2044-2055. doi:10.1016/j. neubiorev.2012.07.005.

Croonenberghs, J., Bosmans, E., Deboutte, D., Kenis, G., \& Maes, M. (2002). Activation of the inflammatory response system in autism. Neuropsychobiology, 45(1), 1-6. doi:10.1159/000048665.

Dawson, G. (2008). Early behavioral intervention, brain plasticity, and the prevention of autism spectrum disorder. Development and Psychopathology, 20(3), 775-803. doi:10.1017/ S0954579408000370.

Dawson, G., Rogers, S., Munson, J., Smith, M., Winter, J., Greenson, J., ... Varley, J. (2010). Randomized, controlled trial of an intervention for toddlers with autism: the Early Start Denver Model. Pediatrics, 125(1), e17-23. doi:10.1542/peds.2009-0958.

De Theije, C. G. M., Koelink, P. J., Korte-Bouws, G. a H., Lopes da Silva, S., Korte, S. M., Olivier, B., ... Kraneveld, A. D. (2014). Intestinal inflammation in a murine model of autism spectrum disorders. Brain, Behavior, and Immunity, 37, 240-7. doi:10.1016/j.bbi.2013. 12.004 .

Depino, A. (2012). Peripheral and central inflammation in autism spectrum disorders. Molecular and Cellular Neuroscience. doi:10.1016/ j.men.2012.10.003.

Dinarello, C. (2000). Proinflammatory cytokines. CHEST Journal: Impact of Basic Research on Tomorrow's Medicine, 118(2), 503508.

Dowlati, Y., Herrmann, N., Swardfager, W., Liu, H., Sham, L., Reim, E. K., \& Lanctôt, K. L. (2010). A meta-analysis of cytokines in major depression. Biological Psychiatry, 67(5), 446-457. doi:10.1016/j. biopsych.2009.09.033.

El-Ansary, A., \& Al-Ayadhi, L. (2014). GABAergic/glutamatergic imbalance relative to excessive neuroinflammation in autism spectrum disorders. Journal of Neuroinflammation, 11(1), 189. doi:10.1186/ s12974-014-0189-0.

El-baz, F., Elhossiny, R. M., Azeem, Y. A., \& Girgis, M. (2014). Study the effect of hyperbaric oxygen therapy in Egyptian autistic children. The Egyptian Journal of Medical Human Genetics, 15, 155-162.

Emanuele, E., \& Lossano, C. (2007). Pioglitazone as a therapeutic agent in autistic spectrum disorder. Medical Hypotheses, 69(3), 699. doi: 10.1016/J.Mehy.2007.01.018

Fatemi, S. (2009). Multiple pathways in prevention of immune-mediated brain disorders: implications for the prevention of autism. Journal of Neuroimmunology, 217(1-2), 8-9. doi:10.1016/j.jneuroim.2009.09. 011.

Fatemi, S. H., Pearce, D., Brooks, I., \& Sidwell, R. W. (2005). Prenatal viral infection in mouse causes differential expression of genes in brains of mouse progeny: a potential animal model for schizophrenia and autism. Synapse, 57(2), 91-99. doi:10.1002/syn.20162.

Fatemi, S. H., Reutiman, T. J., Folsom, T. D., Huang, H., Oishi, K., Mori, S., ... Juckel, G. (2008). Maternal infection leads to abnormal gene regulation and brain atrophy in mouse offspring: implications for genesis of neurodevelopmental disorders. Schizophrenia Research, 99(1-3), 56-70. doi:10.1016/j.schres.2007.11.018. 
Fatemi, S. H., Aldinger, K. A, Ashwood, P., Bauman, M. L., Blaha, C. D., Blatt, G. J., ... Welsh, J. P. (2012). Consensus paper: pathological role of the cerebellum in autism. Cerebellum, 11(3), 777-807. doi: 10.1007/s12311-012-0355-9.

Fernell, E., Fagerberg, U. L., \& Hellström, P. M. (2007). No evidence for a clear link between active intestinal inflammation and autism based on analyses of faecal calprotectin and rectal nitric oxide. Acta Paediatrica, 96(7), 1076-1079. doi:10.1111/j.1651-2227.2007. 00298.x.

Flanders, S. C., Engelhart, L., Whitworth, J., Hussein, M. A., Vanderpoel, D. R., \& Sandman, T. (2006). The economic burden of pervasive developmental disorders in a privately insured population. Managed Care Interface, 19(8), 39.

Garay, P., Hsiao, E., Patterson, P., \& McAllister, A. (2012). Maternal immune activation causes age- and region-specific changes in brain cytokines in offspring throughout development. Brain, Behavior, and Immunity. doi:10.1016/j.bbi.2012.07.008.

Geschwind, D. H. (2009). Advances in autism. Annual Review of Medicine, 60, 367-380. doi:10.1146/annurev.med.60.053107. 121225 .

Ghanizadeh, A. (2010). Methionine sulfoximine may improve inflammation in autism, a novel hypothesized treatment for autism. Archives of Medical Research, 41(8), 651-652. doi:10.1016/j.arcmed.2010. 10.012 .

Goines, P., \& Ashwood, P. (2012). Cytokine dysregulation in autism spectrum disorders (ASD): possible role of the environment. Neurotoxicology and Teratology. doi:10.1016/j.ntt.2012.07.006.

Goldstein, B. I., Kemp, D. E., Soczynska, \& McIntyre, R. S. (2009). Inflammation and the phenomenology, pathophysiology, and comorbidity, and the treatment of bipolar disorder: a systematic review of the literature. Journal of Clinical Psychology, 70(8), 1078-1090.

Granger, J., Osuchowski, M., \& Remick, D. (2006). Differential inflammatory response to LPS and sepsis. SHOCK, 25(Supplement 1), 9798. doi:10.1097/00024382-200606001-00294.

Grigorenko, E., Han, S., Yrigollen, C., Leng, L., Mizue, Y., Anderston, G., Mulder, E., de Bildt, A., Minderaa, R., Volkmar, F., Chang, J., \& Bucala, R. (2008). Macrophage migration inhibitory factor and autism spectrum disorders. Pediatrics, 122, e438-e445.

Herbert, M., Russo, J., Yang, S., Roohi, J., Blaxill, M., Kahler, S., . . . Hatchwell, E. (2006). Autism and environmental genomics. Neurotoxicology, 27(5), 671-684. doi: 10.1016/j.neuro.2006.03. 017.

Hood, K. E., Dreschel, N. A., \& Granger, D. A. (2003). Maternal behavior changes after immune challenge of neonates with developmental effects on adult social behavior. Developmental Psychobiology, 42(1), 17-34. doi:10.1002/dev.10076.

Hu, V., Frank, B., Heine, S., Lee, N., \& Quackenbush, J. (2006). Gene expression profiling of lymphoblastoid cell lines from monozygotic twins discordant in severity of autism reveals differential regulation of neurologically relevant genes. BMC Genomics, 7. doi: 10.1186/ 1471-2164-7-118.

Hussman, J. P. (2001). Suppressed GABAergic inhibition as a common factor in suspected etiologies of autism. Journal of Autism and Developmental Disorders, 31(2), 247-248.

Jepson, B., Granpeesheh, D., Tarbox, J., Olive, M. L., Stott, C., Braud, S., . . Allen, M. S. (2011). Controlled evaluation of the effects of hyperbaric oxygen therapy on the behavior of 16 children with autism spectrum disorders. Journal of Autism and Developmental Disorders, 41(5), 575-588. doi:10.1007/s10803-010-1075-y.

Jyonouchi, H., Sun, S., \& Le, H. (2001). Proinflammatory and regulatory cytokine production associated with innate and adaptive immune responses in children with autism spectrum disorders and developmental regression. Neuroimmunology, 120, 170-179.

Kumar, V., Abbas, A. K., Fausto, N., Robbins, S. L., \& Cotran, R. S. (2005). Robbins and cotran pathologic basis of disease. Philadelphia: Elsevier Saunders.
Kunz, T., \& Oliw, E. (2001). The selective cyclooxygenase-2 inhibitor rofecoxib reduces kainate-induced cell death in the rat hippocampus. Neuroscience, 13, 569-575.

Lintas, C., Altieri, L., Lombardi, F., Sacco, R., \& Persico, A. M. (2010). Association of autism with polyomavirus infection in postmortem brains. Journal of Neurovirology, 16(2), 141-149. doi:10.3109/ 13550281003685839.

Lotrich, F. E., Rabinovitz, M., Gironda, P., \& Pollock, B. G. (2007). Depression following pegylated interferon-alpha: characteristics and vulnerability. Journal of Psychosomatic Research, 63(2), 131135. doi:10.1016/j.jpsychores.2007.05.013.

Lotrich, F. E., Ferrell, R. E., Rabinovitz, M., \& Pollock, B. G. (2009). Risk for depression during interferon-alpha treatment is affected by the serotonin transporter polymorphism. Biological Psychiatry, 65(4), 344-348. doi:10.1016/j.biopsych.2008.08.009.Risk.

Lucchina, L., Carola, V., Pitossi, F., \& Depino, A. M. (2010). Evaluating the interaction between early postnatal inflammation and maternal care in the programming of adult anxiety and depression-related behaviors. Behavioural Brain Research, 213(1), 56-65. doi:10. 1016/j.bbr.2010.04.032.

Luqman, S., \& Pezzuto, J. (2010). NFkappaB: a promising target for natural products in cancer chemoprevention. Phytotherapy Research, 24(7), 949-963. doi:10.1002/ptr.3171.

Malkova, N. V., Yu, C. Z., Hsiao, E. Y., Moore, M. J., \& Patterson, P. H. (2013). Maternal immune activation yields offspring displaying mouse versions of the three core symptoms of autism. Brain, Behavior, and Immunity, 26(4), 607-616. doi:10.1016/j.bbi.2012. 01.011.Maternal.

Mandell, D. S., Cao, J., Ittenbach, R., \& Pinto Martin, J. (2006). Medicaid expenditures for children with autistic spectrum disorders: 1994 to 1999. Journal of Autism and Developmental Disorders, 36(4), 47585. doi:10.1007/s10803-006-0088-z.

Matson, J., \& Fodstad, J. (2009). The treatment of food selectivity and other feeding problems in children with autism spectrum disorders. Research in Autism Spectrum Disorders, 3(2), 455-461. doi:10. 1016/J.Rasd.2008.09.005.

Merchant, M. L., \& Klein, J. B. (2011). Urinary proteomics and candidate biomarker discovery for diabetic nephropathy. In C. L. Edelstein (Ed.), Biomarkers in kidney disease (pp. 351-366). Cincinnati: University of Cincinnati School of Medicine, Academic Press.

Meyer, U., Feldon, J., \& Dammann, O. (2011). Schizophrenia and autism: both shared and disorder-specific pathogenesis via perinatal inflammation? Pediatric Research, 69(5 Pt 2), 26R-33R. doi:10. 1203/PDR.0b013e318212c196.

Miller, A. H., Maletic, V., \& Raison, C. L. (2009). Inflammation and its discontents: the role of cytokines in the pathophysiology of major depression. Biological Psychiatry, 65(9), 732-741. doi:10.1016/j. biopsych.2008.11.029.

Miller-Keane \& O'Toole, M.T. (2005). Encyclopedia and dictionary of medicine, nursing, and allied health (7th Ed.). Philadelphia: Elsevier Health Sciences.

Mitchell, R. H. B., \& Goldstein, B. I. (2014). Inflammation in children and adolescents with neuropsychiatric disorders: a systematic review. Journal of the American Academy of Child and Adolescent Psychiatry, 53(3), 274-296. doi:10.1016/j.jaac.2013.11.013.

Mulloy, A., Lang, R., O'Reilly, M., Sigafoos, J., Lancioni, G., \& Rispoli, M. (2010). Gluten-free and casein-free diets in the treatment of autism spectrum disorders: a systematic review. Research in Autism Spectrum Disorders, 4(3), 328-339. doi:10.1016/J. Rasd. 2009.10.008.

Murray, S. A., Morgan, J. L., Kane, C., Sharma, Y., Heffner, C. S., Lake, J., \& Donahue, L. R. (2010). Mouse gestation length is genetically determined. PLoS One, 5(8), e12418. doi:10.1371/journal.pone. 0012418

Naik, U., Gangadharan, C., Abbagani, K., Nagalla, B., Dasari, N., \& Manna, S. (2011). A study of nuclear transcription factor-kappa B in childhood autism. PLoS One, 6, e19488. 
Napolioni, V., Ober-Reynolds, B., Szelinger, S., Corneveaux, J., Pawlowski, T., Ober-Reynolds, S., . . Huentelman, M. (2013). Plasma cytokine profiling in sibling pairs discordant for autism spectrum disorder. Journal of Neuroinflammation, 10(1), 38-38. doi:10. 1186/1742-2094-10-38.

Nasu, K., Itoh, H., Yuge, A., Nishida, M., \& Narahara, H. (2007). Human oviductal epithelial cells express Toll-like receptor 3 and respond to double-stranded RNA: fallopian tube-specific mucosal immunity against viral infection. Human Reproduction (Oxford, England), 22(2), 356-361. doi:10.1093/humrep/del385.

Noriega, D. B., \& Savelkoul, H. F. J. (2014). Immune dysregulation in autism spectrum disorder. European Journal of Pediatrics, 173(1), 33-43. doi:10.1007/s00431-013-2183-4.

Nuzzo, D., Picone, P., Caruana, L., Vasto, S., Barera, A., Caruso, C., \& Di Carlo, M. (2014). Inflammatory mediators as biomarkers in brain disorders. Inflammation, 37(3), 639-648. doi:10.1007/s10753-0139780-2.

Owens, D. F., \& Kriegstein, A. R. (2002). Is there more to GABA than synaptic inhibition? Nature Reviews Neuroscience, 3(9), 715-727.

Pacheco, R., Gallart, T., Lluis, C., \& Franco, R. (2007). Role of glutamate on T-cell mediated immunity. Journal of Neuroimmunology, 185(12), 9-19. doi:10.1016/j.jneuroim.2007.01.003.

Patterson, P. (2009). Immune involvement in schizophrenia and autism: etiology, pathology and animal models. Behavioural Brain Research, 204(2), 313-321. doi:10.1016/J.Bbr.2008.12.016.

Potvin, S., Stip, E., Sepehry, A., Gendron, A., Bah, R., \& Kouassi, E. (2008). Inflammatory cytokine alterations in schizophrenia: a systematic quantitative review. Biological Psychiatry, 63(8), 801-808. doi:10.1016/j.[)iopsych.2007-09.024.

Prandota, J. (2010). Autism spectrum disorders may be due to cerebral toxoplasmosis associated with chronic neuroinflammation causing persistent hypercytokinemia that resulted in an increased lipid peroxidation, oxidative stress, and depressed metabolism of endogenous and exogenous substances. Research in Autism Spectrum Disorders, 4(2), 119-155. doi:10.1016/J.Rasd.2009.09.011.

Raven, P., Johnson, G., Mason, K., Losos, J., \& Singer, S. (2011). Biology (9th ed.). New York: McGraw-Hill.

Rees, S., \& Inder, T. (2005). Fetal and neonatal origins of altered brain development. Early Human Development, 81(9), 753-761. doi:10. 1016/j.earlhumdev.2005.07.004.

Ricci, S., Businaro, R., Ippoliti, F., Lo Vasco, V. R., Massoni, F., Onofri, E., ... Archer, T. (2013). Altered cytokine and BDNF levels in autism spectrum disorder. Neurotoxicity Research, 24(4), 491-501. doi:10.1007/s 12640-013-9393-4.

Roberts, M., Bentley, M., \& Harris, J. (2002). Chemistry for peptide and protein PEGylation. Advanced Drug Delivery Reviews, 54(4), 459476. doi:10.1016/S0169-409x(02)00022-4.

Rommelse, N., Geurtsc, H., Frankea, B., Buitelaarb, J., \& Hartman, C. (2011). A review on cognitive and brain endophenotypes that may be common in autism spectrum disorder and attention-deficit/hyperactivity disorder and facilitate the search for pleiotropic genes. Neuroscience \& Biobehavioral Reviews, 35(6), 1363-1396.

Rose, S., Melnyk, S., Pavliv, O., Bai, S., Nick, T., Frye, R., \& James, S. (2012). Evidence of oxidative damage and inflammation associated with low GSH redox status in the autism brain. Translations Psychiatry, 2, e134. doi:10.1038/tp.2012.61.

Rossignol, D. (2009). Novel and emerging treatments for autism spectrum disorders: a systematic review. Annals of Clinical Psychiatry, 21(4), 213-236.

Rossignol, D., \& Frye, R. E. (2014). Evidence linking oxidative stress, mitochondrial dysfunction, and inflammation in the brain of individuals with autism. Frontiers in Physiology, 5, 150. doi:10.3389/ fphys.2014.00150.

Rossignol, D., \& Rossignol, L. (2006). Hyperbaric oxygen therapy may improve symptoms in autistic children. Medical Hypotheses, 67(2), 216-228. doi:10.1016/j.mehy.2006.02.009.
Rossignol, D., Rossignol, L., James, S., Melnyk, S., \& Mumper, E. (2007). The effects of hyperbaric oxygen therapy on oxidative stress, inflammation, and symptoms in children with autism: an open-label pilot study. BMC Pediatrics, 7, 36. doi:10.1186/14712431-7-36.

Rossignol, D., Rossignol, L., Smith, S., Schneider, C., Logerquist, S., Usman, A., . . Mumper, E. (2009). Hyperbaric treatment for children with autism: a multicenter, randomized, double-blind, controlled trial. BMC Pediatrics, 9, 21. doi: 10.1186/1471-2431-9-21.

Rossignol, D., Bradstreet, J., Van Dyke, K., Schneider, C., Freedenfeld, S., O'Hara, N., . . . Frye, R. (2012). Hyperbaric oxygen treatment in autism spectrum disorders. Medical Gas Research, 2(1), 16. doi: 10. 1186/2045-9912-2-16.

Ruggeri, B., Sarkans, U., Schumann, G., \& Persico, A. M. (2014). Biomarkers in autism spectrum disorder: the old and the new. Psychopharmacology, 231(6), 1201-1216. doi:10.1007/s00213013-3290-7.

Sareddy, G., Geeviman, K., Ramulu, C., \& Babu, P. (2012). The nonsteroidal anti-inflammatory drug celecoxib suppresses the growth and induces apoptosis of human glioblastoma cells via the NF-kappaB pathway. Neurooncology, 106, 99-109.

Schmidt (2006). Signs of the times: biomarkers in perspective. Environmental Health Perspective, 114(12), A700-A705.

Scifo, R., Cioni, M., Nicolosi, A., Batticane, N., Tirolo, C., Testa, N., . . . Marchetti, B. (1996). Opioid-immune interactions in autism: behavioural and immunological assessment during a double-blind treatment with naltrexone. Annali dell'Istituto Superiore di Sanita, 32(3), 351-359.

Serafini, M., Peluso, I., \& Raguzzini, A. (2010). Session 1: Antioxidants and the immune system flavonoids as anti-inflammatory agents. Proceedings of the Nutrition Society, 69(3), 273-278. doi:10.1017/ S002966511000162x.

Shenoy, S., Arnold, S., \& Chatila, T. (2000). Response to steroid therapy in autism secondary to autoimmune lymphoproliferative syndrome. Journal of Pediatrics, 136(5), 682-687. doi:10.1067/Mpd.2000. 105355.

Shi, L., Smith, S. E. P., Malkova, N., Tse, D., Su, Y., \& Patterson, P. H. (2009). Activation of the maternal immune system alters cerebellar development in the offspring. Brain, Behavior, and Immunity, 23(1), 116-123. doi:10.1016/j.bbi.2008.07.012.

Singh, K., Connors, S. L., Macklin, E. A., Smith, K. D., Fahey, J. W., Talalay, P., \& Zimmerman, A. W. (2014). Sulforaphane treatment of autism spectrum disorder (ASD). Proceedings of the National Academy of Sciences, 111(43), 15550-15555. doi:10.1073/pnas. 1416940111.

Skurkovich, S., Skurkovich, B., \& Kelly, J. (2002). Anticytokine therapy - new approach to the treatment of autoimmune and cytokinedisturbance diseases. Medical Hypotheses, 59(6), 770-780.

Stigler, K., Sweeten, T., Posey, D., \& McDougle, C. (2009). Autism and immune factors: a comprehensive review. Research in Autism Spectrum Disorders, 3(4), 840-860. doi:10.1016/J.Rasd.2009.01. 007.

Sudarov, A. (2013). Defining the role of cerebellar Purkinje cells in autism spectrum disorders. Cerebellum, 12(6), 950-955. doi:10.1007/ s12311-013-0490-y.

Taylor, L. J., Maybery, M. T., \& Whitehouse, A. J. O. (2014). Moving beyond behaviour-only assessment: incorporating biomarkers to improve the early detection and diagnosis of autism spectrum disorders. International Journal of Speech-Language Pathology, 16(1), 19-22. doi:10.3109/17549507.2013.855262.

Thom, S. R. (2011). Hyperbaric oxygen - its mechanisms and efficacy. Plastic and Reconstructive Surgery, 127(Suppl 1), 131S-141S. doi: 10.1097/PRS.0b013e3181fbe2bf.

Tian, J., Kim, S., Hester, L., \& Snyder, S. (2008). S-nitrosylation/activation of COX-2 mediates NMDA neurotoxicity. Proceedings of the 
National academy of Sciences of the United States of America, 105, 10537-10540.

Toledo, E., Lebel, A., Becerra, L., Minster, A., Linnman, C., Maleki, N., . . . Borsook, D. (2012). The young brain and concussion: imaging as a biomarker for diagnosis and prognosis. Neuroscience and Biobehavioral Reviews, 36(6), 1510-1531. doi: 10.1016/J.Neubiorev.2012.03.007.

Tuchman, R., Cuccaro, M., \& Alessandri, M. (2010). Autism and epilepsy: historical perspective. Brain Dev, 32(9), 709-718. doi:10.1016/j. braindev.2010.04.008

U.S. Food and Drug Administration (2013). Hyperbaric oxygen therapy: don't be misled. FDA Consumer Health Information, 1-2.

Vargas, D., Nascimbene, C., Krishnan, C., Zimmerman, A., \& Pardo, C. (2005). Neuroglial activation and neuroinflammation in the brain of patients with autism. Annals of Neurology, 57(1), 67-81. doi:10. 1002/Ana.20397.

Walsh, P., Elsabbagh, M., Bolton, P., \& Singh, I. (2011). A response to Pellicano, et al. (2011). Nature Reviews Neuroscience, 12, 769.

Wang, F., Wu, H., Xu, S., Guo, X., Yang, J., \& Shen, X. (2011). Macrophage migration inhibitory factor activates cyclooxygenase 2-prostaglandin E2 in cultured spinal microglia. Neuroscience Research, 71, 210-218.
Watzl, B. (2008). Anti-inflammatory effects of plant-based foods and of their constituents. International Journal for Vitamin and Nutrition Research, 78(6), 293-298. doi:10.1024/0300-9831.78.6.293.

Wei, H., Zou, H., Sheikh, A., Malik, M., Dobkin, C., Brown, W., \& Li, X. (2011). IL-6 is increased in the cerebellum of autistic brain and alters neural cell adhesion, migration and synaptic formation. Neuroinflammation, 8(52).

Whitehouse, A. J. O. (2013). Complementary and alternative medicine for autism spectrum disorders: rationale, safety and efficacy. Journal of Paediatrics and Child Health, 49(9), E438-E442. doi:10.1111/ jpc. 12242.

Whiteley, P., Shattock, P., Knivsberg, A.-M., Seim, A., Reichelt, K. L., Todd, L., ... Hooper, M. (2013). Gluten- and casein-free dietary intervention for autism spectrum conditions. Frontiers in Human Neuroscience, 6, 344. doi:10.3389/fnhum.2012.00344.

Wiggins, L. D., Robins, D. L., Adamson, L. B., Bakeman, R., \& Henrich, C. C. (2012). Support for a dimensional view of autism spectrum disorders in toddlers. Journal of Autism and Developmental Disorders, 42(2), 191-200. doi:10.1007/s10803-011-1230-0.

Younger, J., Parkitny, L., \& McLain, D. (2014). The use of low-dose naltrexone (LDN) as a novel anti-inflammatory treatment for chronic pain. Clinical Rheumatology, 33(4), 451-459. doi:10.1007/ s10067-014-2517-2. 